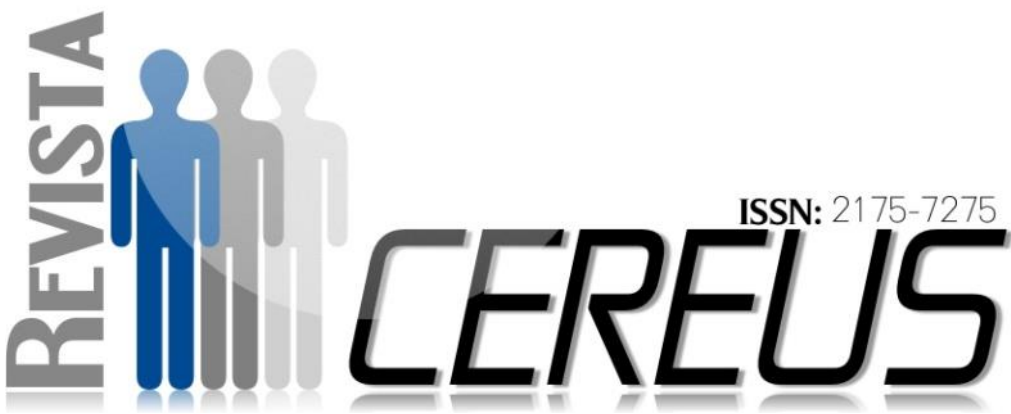

\section{O LIVRO DO DESASSOSSEGO: ASPECTOS ESTRUTURAIS DE UMA NARRATIVA FRAGMENTADA}

\author{
GOMES, Edivam Pereira ${ }^{1}$ \\ OLIVEIRA, Maria Wellitanea de ${ }^{2}$
}

RESUMO

Este artigo apresenta a análise do Livro do Desassossego, de Bernardo Soares, heterônimo de Fernando Pessoa, com o objetivo de compreender alguns aspectos da personalidade do autor e a construção de sua narrativa. Tem-se como pressuposto geral, a ideia de que os processos de construção literária em Fernando Pessoa constituem-se de uma autobiografia subjetiva que expressa seu estado emocional. A relevância deste estudo consiste no aprendizado que 0 leitor pode adquirir ao ler a escrita pessoana, em que o poeta, por meio de uma narrativa fragmentada, mostra que a arte literária é a manifestação da alma e da inteligência humana, que se cria a partir de um recorte da realidade. Assim, na fundamentação deste trabalho, utilizou-se de teorias de vários estudiosos em Fernando Pessoa, tais como: BACHELARD

${ }^{1}$ Graduado em Letras - Português/Inglês pelo Centro Universitário UnirG - Gurupi.

2 Professora Universitária no Centro Universitário UnirG; Graduada em Letras - Português pela Ulbra; Mestra em Teoria e Crítica Literária pela UCG; Especialista em Metodologia do Ensino de Língua Portuguesa e Literaturas pelo Ibepex. Profissional voltada para área de pesquisa e ensino. Email para correspondência: Wellitania2011@live.com 
(2006); BAKHTIN (1998); CUNHA (2005); KEATING (2006); JUNG (2005); MARTINS (2010); SEABRA (1988) entre outros.

Palavras chave: Livro do Desassossego. Heterônimo. narrativa fragmentada.

\section{THE BOOK OF DISASSOSURE: STRUCTURAL ASPECTS OF A FRAGMENTED NARRATIVE}

\section{ABSTRACT}

This article presents the analysis of the Book of Disassosure, by Bernardo Soares, heteronymous by Fernando Pessoa, with the aim of understanding some aspects of the author's personality and the construction of his narrative. The general assumption is that the processes of literary construction in Fernando Pessoa are a subjective autobiography that expresses his emotional state. The relevance of this study is the learning that the reader can acquire when reading personal writing, in which the poet, through a fragmented narrative, shows that literary art is the manifestation of the soul and of human intelligence, which is created from a piece of reality. Thus, in the foundation of this work, the theories of several scholars in Fernando Pessoa were used, such as: BACHELARD (2006); BAKHTIN (1998); CUNHA (2005); KEATING (2006); JUNG (2005); MARTINS (2010); SEABRA (1988), among others.

Keywords: Book of Disassosure. Heteronymous.

Fragmented narrative. 


\section{INTRODUÇÃO}

Fernando Pessoa é o nome mais representativo do Modernismo português, movimento literário que teve início em 1915, com a publicação da revista Orpheu. Nesse período, a Europa estava em plena Guerra Mundial, que eclodiu um ano antes (1914). Portugal vivia os primeiros anos da República de (1910), em meio à turbulências do momento aflora um nacionalismo cáustico, que reflete na literatura o desejo de mudança, por meio dos manifestos publicados por escritores de vanguarda. É nesse contexto que surge Fernando Pessoa com seus heterônimos que são muitos, mais de setenta, dos quais os mais conhecidos são Alberto Caeiro, Álvaro de Campos, Ricardo Reis e Bernardo Soares, sendo este último o autor do Livro do Desassossego, o qual é a referência para este estudo.

O Livro do Desassossego, assinado pelo semi-heterônimo Bernardo Soares, criação de Fernando Pessoa, apresenta o reflexo de um homem, cuja existência solitária levouo a viver num mundo imaginário, numa
Lisboa fictícia, pacata, que serve de inspiração para o poeta observar os transeuntes a ir e vir pelas ruas da cidade. Acredita-se que o Livro é a expressão mascarada do hortônimo Fernando Pessoa, pois apresenta traços marcantes do poeta. Nele, a heteronímia sugere entendimentos acerca da relação obra e autor. A essência do poeta aparece nas entrelinhas da narrativa, de forma velada.

A obra apresenta uma rica produção literária - na estrutura física, nas reflexões dos contextos apresentados - que faz com que o leitor sinta a transcendência das sensações de inquietação transmitida em meio à leitura dos textos, o que justifica o título dado à obra.

Por meio de uma narrativa fragmentada e ideias que expressam a relação entre a biografia e a arte ficcional, o Livro do Desassossego mostra que a arte literária é a manifestação da alma e da inteligência humana, que se cria a partir de um recorte da realidade. 


\section{METODOLOGIA}

A ênfase deste estudo se fez por meio da observação teórico-analítico, tomando como ferramenta a metodologia de análise qualitativa, a fim de elucidar a questão levantada acerca da produção literária de Fernando Pessoa. O processo analítico buscou evidenciar os sentidos produzidos no discurso literário do Livro do Desassossego e, também, observou-se questões relacionadas ao caráter textual do ponto de vista do estilo literário e da percepção da identidade do poeta hortônimo na obra assinada pelo heterônimo.

Sobre a pesquisa qualitativa, Eduardo Moresi considera que,

há uma relação dinâmica entre o mundo real e o sujeito, isto é, um vínculo indissociável entre o mundo objetivo e a subjetividade do sujeito que não pode ser traduzido em números. A interpretação dos fenômenos e a atribuição de significados são básicas no processo de pesquisa qualitativa. Não requer o uso de métodos e técnicas estatísticas. $\mathrm{O}$ ambiente natural é a fonte direta para coleta de dados e o pesquisador é o instrumento-chave. É descritiva. Os pesquisadores tendem a analisar seus dados indutivamente. O processo e seu significado são os focos principais de abordagem (MORESI, 2003, p. 8-9).
Assim sendo, o trabalho teve início por meio de pesquisa bibliográfica com a análise do Livro do Desassossego, embasando-se em estudiosos que já pesquisaram sobre Fernando Pessoa. Esse tipo de pesquisa, também se caracteriza como pesquisa básica, pois objetiva demonstrar conhecimentos novos para o progresso nos estudos.

Para Moresi, a pesquisa bibliográfica

é o estudo sistematizado desenvolvido com base em material publicado em livros, revistas, jornais, redes eletrônicas, isto é, material acessível ao público em geral. Fornece instrumental analítico para qualquer outro tipo de pesquisa, mas também pode esgotar-se em si mesma (MORESI, 2003, p. 10).

Dessa forma, a pesquisa bibliográfica consiste no recurso básico para os estudos monográficos, pelo qual se busca a compreensão de teórico e prática sobre determinado tema. Assim, a pesquisa também é exploratória e se apoia em críticos literários e estudiosos das diversas áreas do conhecimento como a psicologia e a filosofia, em busca de encontrar respostas para o problema sugerido desde o início deste estudo. 


\section{DESENVOLVIMENTO}

O entendimento da literatura como objeto de representação da realidade, que muitas vezes se quer ocultar, pode ser a base para a concepção de heterônimos, poetas concebidos por um poeta, como fez o escritor português Fernando Pessoa ao criar vários poetas com características e personalidades diferentes. "Criei em mim várias personalidades. Crio personalidades constantemente. [...] Sou a cena nua onde passam vários atores representando várias peças", afirmou o próprio Pessoa (2011, p.288).

Ao criar 0 Livro do Desassossego, Fernando Pessoa criou mais que uma literatura, segundo alguns estudiosos, trata-se de uma autobiografia. Por isso, estudar a obra de Fernando Pessoa não é apenas conhecer o maior poeta do Modernismo português, mas é adentrar no mundo de um dos autores extremamente controvertido e de uma obra múltipla, paradoxal e ambígua.

Cunha (2005) afirma que para compreender o Livro do Desassossego é necessário montar peças para formar um conjunto, isto é, um "quebracabeça". Ainda segundo o mesmo autor, "A pesquisa de suas edições e de boa parte de sua fortuna crítica foi um passo importante para entender o Livro. Todavia, não foi encontrado um texto único que contasse a sua história". (CUNHA, 2005, p. 75).

De acordo com Martins (2010), ainda em vida, Fernando Pessoa publicou, a partir de 1913, doze textos (fragmentos) do Livro do Desassossego, em algumas revistas da época:

\begin{abstract}
A Águia [...] com o título Na Floresta do Alheamento [...] intitulado como do Livro do Desassossego, em preparação. [...] Os restantes [...] dois em 1929 (na Revista da 'Solução Editor'), um em 1930 (na Presença 27), cinco em 1931 (na Descobrimento, vol. I), e três em 1932 (na presença 34, na Revolução e na Revista Editorial). (MARTINS, 2010, p. 413-416).
\end{abstract}

Percebe-se, que mesmo em produção o Livro do Desassossego ganhava vida a cada texto publicado nas revistas. No entanto, alguns textos ainda estavam por publicar, pois, após o falecimento do poeta, foram encontrados vários fragmentos de textos, em uma arca pertencente a Fernando Pessoa, uns datados, outros sem data, referidos como ( $L$ do $D$ ) compreendidos como partes do Livro do Desassossego. Segundo Martins o livro "É uma escrita diarística, 
registrando não os acontecimentos de uma vida, mas sim as suas sensações e reflexões" (Idem, p. 815).

Já sobre a publicação, o livro foi montado e editado postumamente sendo a primeira publicação em "1938, com fragmentos incluídos na revista Mensagem (sob o título Diário Lúcido, da responsabilidade da revista, igualmente atribuída a autoria a Vicente Guedes)". No entanto, Em 1961, Pedro Veiga fez a reedição com o título "Livro do Desassossego" (Idem, p. 416).

Atualmente 0 Livro do Desassossego já publicado em vários países e a cada tradução e publicação da obra continua a gerar inquietação diante dos tradutores e organizadores; instiga 0 leitor/pesquisador a compreender Pessoa, além de provocá-lo a imaginar sobre o que diz as entrelinhas do texto. Como diz Bachelard, "um livro é a vida exprimida, portanto, um aumento da vida". (2006, p. 88). Talvez, por isso, a leitura do Livro do desassossego provoca 0 senso crítico do leitor e causa incertezas a todo aquele que busca decifrá-lo e organizá-lo. Segundo Zenith, um dos organizadores do Livro do Desassossego, a criação de Pessoa não pode ser considerada uma concepção comum, dada a dificuldade em organizar textualmente a obra, considerada por Zenith "um não-livro" (PESSOA, 2011, p. 15).

Já outros autores consideram a obra uma autobiografia. O próprio Pessoa faz subentender esse fato em um fragmento onde relata a vida de Soares como sendo "A autobiografia de alguém que nunca teve vida" (Idem, $p$. 494). Comparado com a vida do Poeta, - Livro do Desassossego, pode ser visto como o reflexo entre o criador e a sua criação, transmitido por meio da fragmentação textual, em que não há uma narrativa linear, nem um final aos modos das narrativas tradicionais.

Sobre os critérios para organizar e editar o Livro do Desassossego, cada estudioso, segundo seu entendimento, monta o livro com o propósito de agradar o leitor interessado em conhecer as ideias de Fernando Pessoa. Zenith, um desses estudiosos, optou por seguir o direcionamento dado pelo próprio Fernando Pessoa, que deixou a autoria do livro, unicamente a Bernardo Soares. Zenith também inseriu no livro cartas do autor, em que - mesmo relata as sensações causadas pela difícil produção da obra (MARTINS, 2010 p. 417).

De acordo com Martins, a obra, que fora iniciada por Pessoa, "passou a 
ser atribuída a Vicente Guedes em 1915, ou talvez ainda em 1914. Vicente Guedes, personagem literária surgida por volta de 1909 como poeta, contista e tradutor, [...] 'ajudante de guarda livros' e morador num $4^{\circ}$ andar da 'Baixa lisboeta"'. Martins afirma ainda, que "As evidências dos manuscritos sugerem que o Livro do Desassossego entrou num estado de dormência a partir de 1921, para ressurgir oito anos depois, assinado por Bernardo Soares, que teve a mesma profissão que seu antecessor" (Idem, p. 415).

Como já foi dito, o Livro do Desassossego é mais que um livro comum. Pensa-se ser a representação do íntimo de Pessoa, que por vezes desabafa suas angústias e pensamentos sobre si mesmo, o outro e sobre o mundo.

O livro apresenta as características de um diário, por apresentar fragmentos com datas e outros sem, não se sabe o porquê. Em busca de explicar a criação de Pessoa, Martins relata que "O Livro do Desassossego é uma autobiografia menos descritiva do que prescritiva e, mais ainda do que prescritiva, préescrita, como se 0 ato de dizer equivalesse ao de fazer, ao de viver". Martins afirma que a obra de Pessoa equivale não somente ao dito, ou imaginado, mas que o livro se torna real e concreto a partir do instante em que "um organizador intervenha e faça uma escolha dos materiais suscetíveis de inclusão (sem saber ao certo quais o autor teria escolhido), impondo uma ordem ao material escolhido [...]" (MARTINS, 2010, p. 414-415).

Em relação aos aspectos estruturais, o Livro do Desassossego é constituído por uma narrativa fragmentada e apresenta aspectos importantes do Modernismo. Outra característica é a questão da duplicidade, que incide na reprodução de duas realidades. Uma voltada para a verossimilhança e a outra para a fantasia, que se misturam e se fundem. Do mesmo modo, a fragmentação do livro reflete a multiplicidade do poeta hortônimo e as muitas personalidades heterônimas.

Considerando o significado de fragmentação, o dicionário Luft define o ato de fragmentar como: reduzir-se, quebrar-se. $E$ fragmento determinado como "a parte de um todo que foi dividido; fração; pedaços; trecho de uma obra escrita; excerto." (LUFT, 1999).

Sobre o Livro do desassossego, Martins define como um: 
Organismo vivo, funcional, organizado e uno. Pelo contrário, o fragmento pode ser considerado como apenas parte de um todo que se perdeu. [...] Assim, o Livro do Desassossego é constituído por fragmentos que não formam uma totalidade, de resto desejada, prevista, mas nunca alcançada pelo autor. (Idem, p. 294).

Ainda segundo Martins, o fragmento pode ser em uma descrição filosófica da individualidade, ou seja, os pedaços existem para unir seu significado e formar um ser, uma criação. Com outro olhar, sugere-se que os heterônimos em conjunto se tornam somente um sujeito. Assim, a estrutura fragmentada do Livro do Desassossego, suscita a ideia de ser a expressão das muitas personalidades do poeta, ou a representação de sua heteronímia.

Martins a fim de entender a heteronímia e o caminho mais coerente para realizar a leitura do livro, perguntase: - "É mais difícil dizer se a heteronímia pessoana constitui uma totalidade (organizada por um eixo narrativo) ou deve ser lida a partir das obras isoladas (fragmentos)?" (Idem, p. 295). É difícil responder, pois assim como sua criação Pessoa é amplo, cabe a cada leitor decidir a maneira que facilitará o seu entendimento das mensagens descritas no livro por Pessoa que, em dados momentos, sugere ao leitor ser um médium, quando diz: "parece que tudo passou independente de mim" (PESSOA, 1986, p. 96), o poeta coloca-se como o receptor.

Em relação à questão narrativa, - livro apresenta seus fragmentos desconectados, textos curtos e longos e mensagens subjetivas. As sensações sentidas por Bernardo Soares fazem subentender em muitos momentos, serem as sensações sentidas por Pessoa homem, devido sua necessidade de expelir as diversas personalidades existentes em si. Bernardo Soares expressa sabiamente, como se sente com tantas ideias que o angustiam querendo ser expelidas ao mesmo tempo.

Em o Livro do Desassossego, os textos são declarações e/ou confissões feitas por meio do semi-heterônimo Bernardo Soares, em que o autor trata de responder e questionar pensamentos íntimos em busca de definições, as quais refletem muitas questões como a "Autobiografia" sem fatos, onde ele se apresenta como alguém que nasceu "em um tempo em que a maioria dos jovens haviam perdido a fé em Deus" e se descreve como pertencente "aquela espécie que estão a margem", alguém que vê a vida 
como "uma estalagem" onde tem que se demorar até que chegue a "diligencia do abismo" e "Poderia considerar essa estalagem uma prisão". Neste sentido, Bernardo Soares, além de não crer em Deus não acredita na humanidade, o mundo é uma estalagem, a vida é curta e o abismo é um lugar que não sabe explicar, mas que se alcança com a morte que chega como uma diligencia que o transportará para onde não sabe. O mundo para ele "é uma prisão", esta metáfora pode estar relacionada ao próprio corpo.

O livro contém, também, múltiplas descrições textuais. Nessas múltiplas descrições textuais, percebese a "heterotextualidade, enquanto expressão da transtextualidade, numa prática significante translinguística, colocando em evidência a estrutura da língua. Segundo Seabra, a transtextualidade em Fernando Pessoa é feita, pela lógica poética de "transposição e transformação de elementos que transmigram, numa cadeia citacional circulante, de um "autor" para outro, sem falar das correntes filosóficas, estéticas e literárias de que alguns deles se reclamam" (SEABRA, 1988, p.18). Em outras palavras a heterotextualidade acontece por meio de Bernardo Soares que expressa os vários heterônimos:

Bernardo Soares diz que seu coração esvazia-se [...] como um balde roto (trecho 154) ou que sua vontade é um balde despejado (trecho 78), Alvaro de Campos afirma 'Meu coração é um balde despejado' (em tabacaria) e compara seu pensar a 'um balde que entornou' (num poema datado $1 / 11 / 1934$ ). Se Soares acha que "Nada pesa tanto como 0 afeto alheio e que tanto o amor como o ódio nos oprime" (trecho 348), uma ode de Ricardo Reis (datada de 1/ 11/ 1930) sustenta que 0 mesmo amor que tenham/ Por nós, quer-nos, oprimir-nos". E quanto o guarda-livros deseja ver "tudo pela primeira vez, não [...] como revelações do Mistério, mas diretamente como florações da realidade" (como não pensar nos versos de Alberto Caeiro? (ZENITHE in PESSOA, 2011, p.18).

Nota-se que o texto revela repetições de ideias entre os heterônimos. Assim sendo, sugere-se que o Semi-heterônimo representa outros em si, pondo em evidência o que se chama de "heterotexto", para demonstrar essa separação inseparável. Pessoa multiplica-se, se contradiz, e ao mesmo tempo deixa explícita a conexão existente entre hortônimo e heterônimos.

Desta forma, chega-se ao entendimento de que são personalidades que se expressam com as características diferentes em seus escritos, mas com ideias semelhantes. Assim, ocorre a transtextualidade que promove a transcendência entre os 
autores heterônimos e o hortônimo, seja entre eles e/ou a subjetividade e a realidade interior e exterior de cada autor.

Ainda sobre a narrativa fragmentada, Pessoa descreve suas observações e, em suas descrições, utiliza uma linguagem que sempre o coloca no mesmo patamar do outro podendo ser compreendida como a fala de outro em si, conforme cita:

Entrei no barbeiro no modo de costume [...] Quando sentei na cadeira, perguntei, [...] ao rapaz barbeiro que me ia colocando no pescoço um pano frio e limpo, como ia o colega da cadeira direita, mais velho de espírito, que estava doente. Perguntei-Ihe sem que me pesasse a necessidade de perguntar: ocorreu-me a oportunidade pelo local e a lembrança "Morreu ontem" respondeu sem tom [...] Toda a minha boa disposição irracional morreu de repente [...] Saudades! Tenho-as até do que não foi nada, por uma angustia da fuga do tempo e uma doença do mistério da vida. $O$ velho sem interesse das polainas sujas, que cruzava frequentemente comigo às nove e meia da manhã? [...] $\mathrm{O}$ que é feito de todos eles, que, porque os vi e os tornei a ver, foram parte da minha vida? Amanhã também serei eu me sumirei da Rua do Prata, da Rua dos Doradouros, da Rua dos Fanqueiros. Amanhã também eu - a alma que sente e pensa o universo que sou para mim sim, amanhã eu também serei o que deixou de passar nestas ruas [...]. (PESSOA, 2011, p. 402).

Neste fragmento o autor reflete sobre a vida, e como esta é passageira. Mostra que somos todos frágeis e estamos fadados a sofrer o fato a nós destinados à "Morte".

Enquanto objeto estético, o conteúdo do Livro do Desassossego reflete a penetração do Poeta hortônimo, um homem sensível e espiritual, que através de sua arte escrita expressa a beleza e harmonia da linguagem, mesmo se tratando de textos em prosa. Neste sentido, Bakhtin (1998, p. 69) afirma que "Na obra de arte vocabular, o caráter eventual do objeto estético é particularmente claro: inter-relação da forma e do conteúdo [...] é clara a penetração do autor, um homem corporal, sensível e espiritual, no objeto".

Diante do exposto, pode-se concluir que Fernando Pessoa multiplica-se, tornando-se sempre e mais indecifrável e, ainda, se define como parte de sua criação:

Tornei-me uma figura de livro, uma vida lida. O que sinto é (sem que eu queira) sentindo para escrever que sentiu. O que penso está logo em palavras misturadas com imagens que desfazem, aberto em ritmos que são outra coisa qualquer. (PESSOA, 2011. p. 202/203).

Assim sendo, a dificuldade em definir a real intenção do autor também é expressa nos muitos autores criados por Fernando Pessoa. A estrutura de sua obra, por vezes, é complexa, muito 
próximo do que afirma Jung (2011, p.71). "Começando como uma simples estrutura, ele se transforma em borboleta. Quando falamos em complexidade, queremos dizer que a estrutura é capaz de se expressar de diversas maneiras." No Livro do Desassossego, é possível sentir as sensações inquietantes vividas pelo Poeta, quanto mais há o envolvimento em busca de entendê-lo, menos conclusões se alcançam, pois como em uma metamorfose Pessoa se transforma.

Assim sendo, a leitura do Livro do Desassossego proporciona ao leitor e ao organizador da obra, uma nova concepção sobre o criador e sua criação, que sempre se inova, seja na busca de entendê-lo seja numa nova edição.

\section{CONSIDERAÇÕES FINAIS}

Conclui-se que o Livro do Desassossego é mais que uma criação literária, é um diário, é uma expressão de sonhos e realidade, são devaneios e verdades expressas pelo poeta Fernando Pessoa, que se reflete, na obra, como num espelho. Quanto mais se busca responder as questões provocadas pela obra, mais dúvidas surgem, mais teorias são criadas e poucas são a resposta concretas sobre o autor.

\section{REFERÊNCIAS}

BACHELARD, Gaston. A poética do devaneio / Gaston Bachelard; tradução Antonio de Padua Danesi; revisão da tradução Alain Marcel Mouzat, Mário Laranjeira - 2. Ed. - São Paulo; Martins Fontes, 2006.

BAKHTIN, Mikhail. Questões de Literatura e de Estética: A Teoria do Romance. Mikhail Bakhtin. - 4. ed. Editora Unesco. São Paulo - 1998.

CUNHA, Ana Cristina Comandulli da. Memorial do desassossego: breve história do Livro do Desassossego, de Fernando Pessoa. Rio de Janeiro, 2005. Dissertação de Mestrado em literatura portuguesa Faculdade de Letras, Universidade Federal do Rio de Janeiro, 2005. Disponível em: < www.letras.ufrj.br/posverna/mestrado/CunhaACC.pdf > em 27 de set 2016 
JUNG, Carl Gustav. Aion estudos sobre o símbolo de si-mesmo. Carl Gustav Jung. Traduzido por Pe. Dom Mateus Ramalho Rocha, O.S.B. Volume 9/ 2. editora Vozes LTDA Petrópolis-RJ, 2011.

LUFT, Celso Pedro. Minidicionário Luft. Celso Pedro Luft. Organizado e supervisionado por Lya Luft. 16. ed. Editora ática1999.

MARTINS, Fernando Cabral. Dicionário de Fernando Pessoa e do modernismo português. Cabral Martins (Coord.). - São Paulo: Laya, 2010.

MORESI, Eduardo. Metodologia da Pesquisa. Brasília-DF: UCB/PRPG, 2003.

PESSOA. Fernando. Livro de desassossego: Composto por Bernardo Soares, ajudante de guarda-livros na cidade de Lisboa / Fernando Pessoa; organizado por Richard Zenith. - 3. edição - São Paulo companhia, 2011.

,Fernando. Fernando Pessoa em Prosa volume único. Fernando Pessoa. Organização, introdução e notas de Cleonice Berardinlli. 6. reimpressão. Editora Nova Aguilar S.A. Rio de Janeiro, 1986.

SEABRA, José Augusto. O heterotexto pessoano / José Augusto Seabra. -São Paulo: Perspectiva : Editora da Universidade de São Paulo, 1988. 